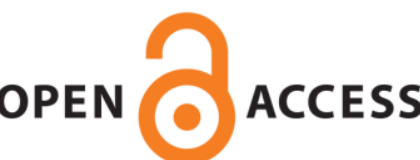

UWS Academic Portal

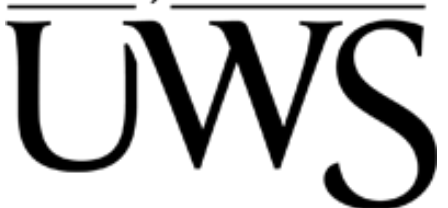

\title{
Introduction to living with advanced dementia series
}

Brown, Margaret; Tolson, Debbie

Published in:

Nursing Older People

DOI:

10.7748/nop.2020.e1169

Published: 01/04/2020

Document Version

Peer reviewed version

Link to publication on the UWS Academic Portal

Citation for published version (APA):

Brown, M., \& Tolson, D. (2020). Introduction to living with advanced dementia series. Nursing Older People, 32(3). https://doi.org/10.7748/nop.2020.e1169

\section{General rights}

Copyright and moral rights for the publications made accessible in the UWS Academic Portal are retained by the authors and/or other copyright owners and it is a condition of accessing publications that users recognise and abide by the legal requirements associated with these rights.

Take down policy

If you believe that this document breaches copyright please contact pure@uws.ac.uk providing details, and we will remove access to the work immediately and investigate your claim. 
This is the author accepted manuscript. The final published version (Version of Record) is available via: https://journals.rcni.com/nursing-older-people/evidence-and-practice/ introduction-to-living-with-advanced-dementia-series-nop.2020.e1169/abs 


\section{Nursing Older People}

\section{Introductory article for the series on advanced dementia: Nursing Older People Advanced Dementia: Achieving Positive Practice \\ --Manuscript Draft--}

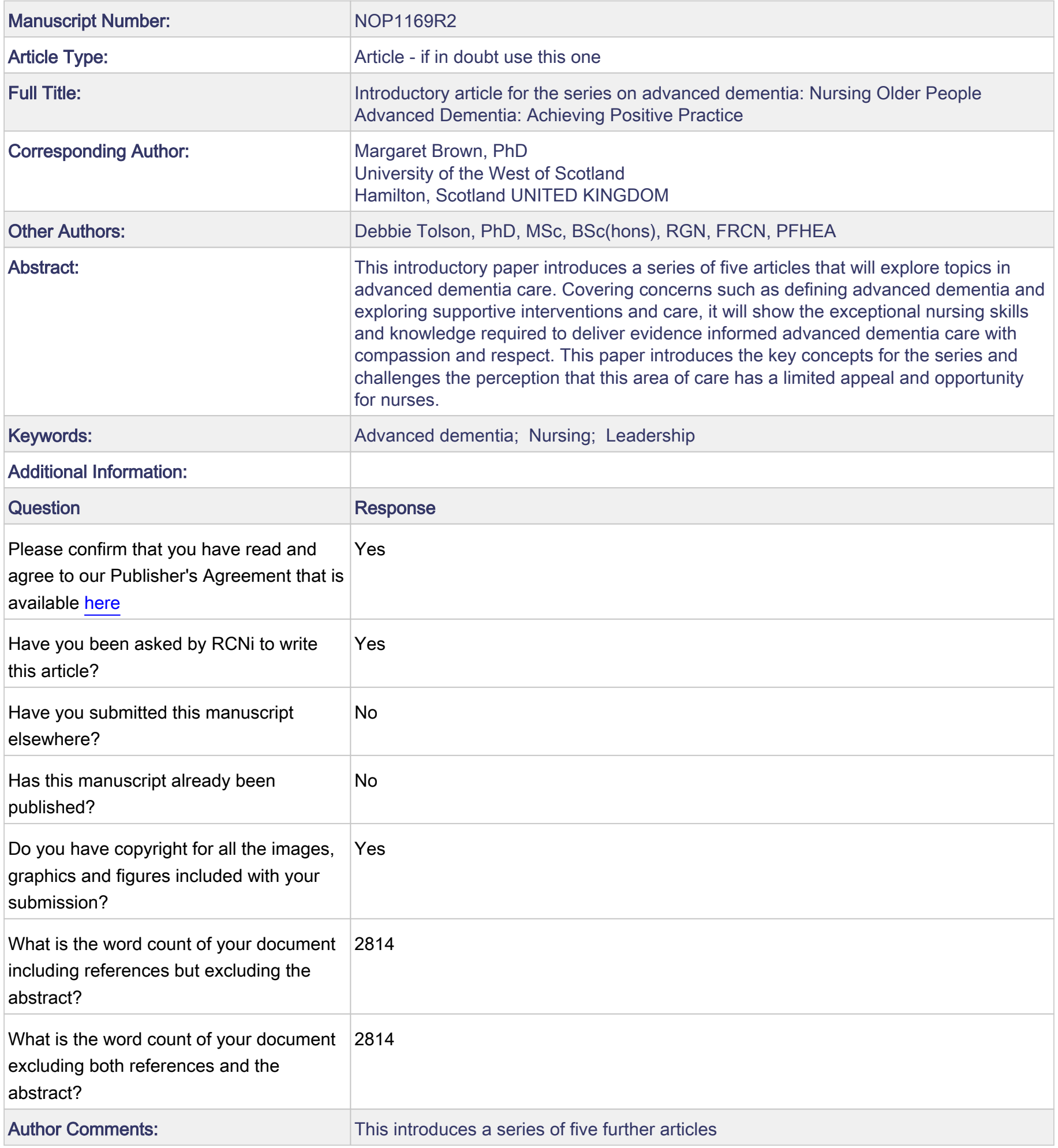


Introductory article for the series on advanced dementia: Nursing Older People

\section{Advanced Dementia: Achieving Positive Practice}

\section{Introduction}

Dementia is caused by illnesses such as Alzheimer's disease, which are neuro progressive and terminal. Alzheimer's disease, vascular dementia, dementia with Lewy bodies and frontotemporal dementia together account for approximately $80 \%$ of dementias (Muangpaisan, 2007). It is one of the main causes of disability in later life, ahead of cancer, cardiovascular disease and stroke and 30\% of people aged 65 years or over will die with dementia (Dixon et al, 2015). Clinical features and symptoms in the advanced stage are complex and associated with the accumulation of irreversible structural and chemical changes in the brain with profound impact on cognition, memory, communication, emotional, sensory and physical functioning. The pattern of cognitive and physical decline is neither fixed nor predictable, and fluctuations in a person's health are common (Alzheimer Scotland, 2015). Although we are learning more about the factors that influence the pace of decline there is currently no known cure (Bartlett et al, 2017), hence the need to pay attention to the development of caring and non-pharmacological interventions (Tolson and Jackson, 2019).

The World Health Organization and Alzheimer's Disease International have described dementia as a public health priority (Wortmann, 2012). By 2025, one million people in the UK are forecast to have some form of dementia, rising to two million by 2051 (Prince et al., 2014). There are currently some 850,000 people in the UK living with dementia (Prince et al., 2014), and within the next ten years it is reasonable to predict that most of these people will be living with advanced dementia and many will require skilled health and social care.

This introductory paper and the five papers in the series that follow, present a care continuum that includes supporting a person to live the best life possible with advanced dementia, through to the end of life. The series reveals the exceptional nursing skills and knowledge that are required to deliver evidence based advanced dementia care with compassion and respect. The purpose of this paper is to provide background information to contextualise advanced dementia and to highlight key challenges facing nurses, nurse educators and nurse leaders.

\section{Advanced dementia described}

There are a number of terms, often used interchangeably, to describe the late stages of the condition, these include 'advanced dementia' (Aminoff, 2014, Nourhashemi et al., 2012, Hanson et al., 2016, Alzheimer Scotland 2019), 'severe dementia' (Nourhashemi et al., 2012, Sampson, 2010), and 'end stage dementia' (Potter et al., 2013). Interestingly, both in UK policy and practice there is no 
authoritative definition of advanced dementia, a situation that some analysts feel has led to inequalities within care systems including unfair charging and a lack of access to expert nursing care (Alzheimer Scotland, 2019). In the next paper in this series, we explore contemporary definitions of advanced dementia, including that presented by the McLeish Commission, which explains advanced dementia as an illness associated with escalating healthcare needs, risks, and dependency (Alzheimer Scotland, 2019). The recent publication of the IDEAL tools for assessment and staging of dementia could, if adopted, begin to address this definitional anomaly and promote greater consistency within policy, practice and research (Semrau et al., 2019).

\section{Palliative and end of life care in advanced dementia}

It is recognised that while dementia is a life limiting illness, there is still controversy regarding the introduction of a palliative care approach that begins at the time of diagnosis (Van der Steen et al., 2015). Nonetheless, while dementia is often describe as a unique experience there is consensus that as dementia advances the goals of care will change, and that palliative and end of life care will have a greater focus. This should include preparing families for loss and death and support after bereavement (Van de Steen et al., 2014).

There is increasing recognition that people can and do live for months and years with advanced dementia-specific palliative care needs (Reisberg et al., 2006) before they reach the stage of dying with dementia. This has prompted international calls for a new narrative to capture the continuum of healthcare needs associated with advanced dementia that includes both living and dying with advanced dementia (Hanson et al., 2016). However, the dementia palliative care trajectory is not straightforward, as some people may live for many years with advanced dementia and some never reach an easily recognisable terminal stage (Van der Steen et al 2017). Determinants of dementia staging are multifaceted and the IDEAL project is one of the few international initiatives, which has embraced the challenge of linking dementia staging with dementia care needs (Semrau et al., 2015). A recent Portuguese study by Abreu et al (2018) recommended that the presence of frailty and escalating functional dependency be seen as key indicators of the transition towards end of life. The outcomes of palliative care in advanced dementia has been the subject of a Cochrane review, which little well designed research about the outcomes of palliative care in advanced dementia, mainly as a result of ethical concerns (Murphy et al., 2016). Further, as van der Steen (2017) explains, the cognitive decline associated with advanced dementia can limit opportunities for individuals to express their own care preferences and highlights the importance of advance care planning. Despite the lack of evidence, Van der Steen et al., (2014) promotes the establishment of discrete new services in palliative care to act as beacons of best practice. Paper five in this series explores palliative and end of life care more fully as a delicate balance required between dementia specific 
care, palliation and the management of other later life conditions and co-morbidities (Tolson et al., 2017). Clearly a balanced and prudent approach, that is exercising good judgement, should be applied across the dementia palliative care trajectory including during care transitions, this means the provision of care should focus on that which is helpful, wanted and as far as possible reflect the preferences of the individual with dementia (Tolson et al., 2016).

\section{Prevalence and Costs of Advanced Dementia}

There are an estimated 50 million people living with dementia worldwide (Prince et al., 2014). In the UK, there are currently approximately 850,000 people with dementia ( $12 \%$ with the advanced condition) with projected numbers set to rise to 1 million by 2025 (Prince et al 2014). Few prevalence studies include people with advanced dementia, those that do exist give higher figures for numbers with advanced dementia than reported by Prince et al (2014) ranging from $17 \%$ to $21 \%$ (Voisin and Vellas, 2009, Schafirovits-Morillo and Suemoto, 2010). Although precise figures are not available, it is generally agreed that age is an important factor with some $20-25 \%$ of people with advanced dementia aged 80 years or above (Lucca et al., 2015). It is important to remember that there are also a growing number of people diagnosed before the age of 65 years; UK estimates indicate that there are currently over 42,000 people with early onset dementia (Alzheimer Society, 2014). Given the numbers, it follows that nurses working in a range of care settings will be major contributors of advanced dementia care and the care of people who are dying of other conditions with dementia.

It has been estimated that dementia costs the UK some $f 26$ billion per year, with 44 per cent attributed to informal care provided by families, 39 per cent social care costs and 16 per cent healthcare costs (Prince et al., 2014). There is a lack of accurate national data upon which to determine with accuracy the costs specifically associated with advanced dementia care. In Scotland, the combined figure for both care home and non-residential advanced dementia care has been estimated at $f 50.9$ Million (Alzheimer Scotland, 2019).

\section{Place of care in advanced dementia}

People nearing the end of their lives with dementia, in any setting, should have their needs assessed and as far as possible their wishes taken into account to enable them to die with dignity in a place of their choosing (National Institute for Care Excellence, 2016). There is a surprising lack of research about the place of care and the impact of where people live with advanced dementia. The place 
where care is provided for people with advanced dementia in the UK is varied and may include the family home, community services including day care, care home, hospital, hospice and specialist NHS continuing care facilities. Hospice care for people with advanced dementia has been reported as an emerging model in the UK (Amador et al., 2016). There is a small but growing number of older people within forensic units, and for these individuals their place of advanced dementia care may include secure units and prisons.

Estimates of the number of care home residents vary, a prevalence study undertaken in England reported that 70 percent of people with dementia live in care homes (Matthews et al., 2013). This is lower than a Scottish study which included clinical assessment with reference to the severity of dementia which found that almost 90 percent of Scottish care home residents have dementia of whom 35\% have advanced dementia (Lithgow et al 2011), .

A recent prospective cohort study of nursing home residents and people living and dying in their own homes with advanced dementia, reported that they often live with chronic and persistent symptoms including agitation and pain (Sampson et al 2018). The commonest physical symptoms on entry to the study reported by Sampson et al (2018) was swallowing difficulties and weight loss, with aspiration and breathing difficulties increasing in the month prior to death.

\section{Policy and drivers}

Given the demographic projections, it is puzzling why there has been so little progress in terms of both planning and delivery of advanced dementia care and services. Particularly, given the increasing numbers of people diagnosed with dementia, the lack of effective treatment and the progressive nature of underlying illnesses.

Scotland's third dementia strategy is one of the few that specifically shines a light on living well with advanced dementia and high quality end of life care (Scottish Government, 2017). The Challenge on Dementia 2020: Implementation plan clearly sets out ambitious commitments for dementia care and research, including the NHS England transformation framework Well Pathway that includes palliative care and dying well with dementia (Gov. UK, 2016) .

The World Health Organization Global Action Plan for Dementia (2017) highlights the importance of care that is dignified and respectful stating that:

“...... for people with dementia and their carers to live well and receive the care and support they need to fulfil their potential to live with dignity, respect autonomy and equality" (World Health Organization, 2017, p4). 
The recent publication in Scotland of the McLeish Report has been an opportunity to address the inequality of access to health care faced by people living with advanced dementia, calling for reforms that include moving beyond social care to recognise the need for health care and nursing (Alzheimer Scotland, 2019).

If nurses took up the mantle of these national and global policy imperatives, there is an amazing opportunity to lead and champion care improvement and care service reform. Leadership is explored further in the last paper of this series, recognising that enabling nurses to respond to this call for action will require both individual and collective action, courage and demonstrable commitment to change.

\section{Education for Practice}

Given that dementia is a major public health challenge it is reasonable for individuals and family carers to assume that nurses who work with people with advanced dementia have the requisite skills and knowledge and a care environment that enables them to provide a high standard of care. Sadly, as media reports continue to highlight, advanced dementia care can all too frequently be conveyed as a catalogue of failures. The reality is that when practitioners lack knowledge, do not have access to expert nurse role models and work in impoverished care environments, the status quo is likely to persist despite our personal and professional good intentions (Hvalič-Touzery et al., 2018). Without in-depth knowledge and understanding of advanced dementia there can be a sense of hopelessness in providing care and a lack of motivation to develop practice. In the care of the person with advanced dementia, there is a pressing need to balance active treatment, enablement and palliative care (Lillo-Crespo et al., 2018); within a social climate, that values functioning, cognition, thinking and memory.

Rigorous approaches to the education of nurses in the care of the person with advanced dementia are urgently needed. Current educational opportunities and resources are variable and there is a sense that any training is better than no training (Hvalič-Touzery et al., 2018). Optimal learning needs to be aligned with knowledge and skills frameworks to increase a shared understanding of best practice and care outcomes (Brown et al., 2018).

A detailed insight into the breadth and depth of the knowledge base required by practitioners to provide informed advanced dementia is contained within The Palliare Best Practice Statement (Holmerova et al., 2016). Dementia Palliare is explained as a positive practice approach to evidenceinformed, interdisciplinary, advanced dementia care. The Palliare Project was completed between 2014-2017 by a partnership of seven European countries (Czech Republic, Finland, Portugal, 
Scotland, Slovenia, Spain and Sweden). The Best Practice Statement, which is offered as a learning framework for practice is divided into six sections covering:

1: Protecting rights, promoting dignity and inclusion

2: Future planning for advanced dementia

3: Managing symptoms and keeping well

4: Living the best life possible

5: Support for family and friends

6: Advancing Dementia Palliare practice (Holmerova et al., 2016).

Each section contains a table corresponding to the 'what, why and how' of best practice. 'What' summarises the content and the role of the professional. 'Why' expands on the reason for the statement. 'How' demonstrates how the statement can be achieved, highlighting the underpinning philosophy of the statement and explicit skill requirements to achieve best practice. One of the merits of the new Palliare narrative is that it reveals the expert knowledge and practical know-how required to deliver good quality advanced dementia care (Hanson et al., 2016). This interprofessional educational framework challenges the lack of practice-based research and the undervaluing and underinvestment in effective practitioner education (Hanson et al., 2016).

The long awaited updated Guideline (NG97) Dementia: assessment, management and support for people living with dementia and their carers published by National Institute of Health and Care Excellence (NICE) (2018), includes useful sections on advanced care planning, palliative care and transitions in care (NICE, 2018). What may disappoint expert nurses and nurse educators is the failure in the NICE recommendations to recognise the distinctive knowledge and skill sets that practitioners require to deliver high quality advanced dementia care. Rather it metaphorically shrugs its shoulders suggesting a 'dementia certificate' is good enough. A question we need to ask, and nurse leaders need to consider, is whether this ambition is aspirational enough and if not, how can we raise the bar?

The UK countries have all addressed educational needs including Making a Difference in Dementia Nursing: Vision and Strategy (Department of Health, 2016) that addresses the need for learning for all nurses in any setting, together with a role for specialist nursing knowledge. In Scotland, the Promoting Excellence Framework details the knowledge and skills all health and social services staff should aspire to achieve, in relation to working with individuals and family carers affected by dementia (Scottish Social Services Council and NHS Education for Scotland, 2011). In Wales, Good Work (Care Council for Wales, 2016) and Northern Ireland's Dementia Learning and Development 
Framework (2016) mirror this generic approach across health and social care and all of these use an incremental knowledge and skills framework, although these are not specifically for nursing. The recent recommendations by the Higher Education Dementia Network (HEDN) suggest that cross referencing these knowledge and skills frameworks throughout the UK, in all health and social care programmes, would enhance the rigour of dementia education (Knifton et al, 2019). As the new standards for pre-registration nursing programmes are published (Nursing and Midwifery Council, 2018) an interesting exercise would be to consider the level of skill that our new nurse registrants should achieve and what is appropriate across the spectrum of nursing roles in different settings where advanced dementia care is delivered.

\section{Concluding Thoughts}

This paper has explored a range of issues around advanced dementia and as understanding has deepened, it has become clear that individuals have a complex and a progressive array of nursing needs, physical, psychological, social, spiritual and existential. Additionally, advanced dementia is experienced by an individual and their family members in different ways and it is important that nurses consider these relationships within care and caring as well as continually developing skills and knowledge in managing the spectrum of dementia related symptoms, including pain and distress. Together the papers in this series challenge nurses at all stages in their career to be intolerant of mediocre advanced dementia care and strive for evidence informed best practice delivered with compassion and dignity. 


\section{References}

Alzheimer Scotland (2015) Advanced Dementia Practice Model of Care. Available at:

http://www.alzscot.org/campaigning/advanced dementia model [Last accessed $6^{\text {th }}$ March 2019]

Alzheimer Scotland (2019) Delivering Fair Dementia Care for People with Advanced Dementia: The

Fair Dementia Care Commission. Available at: https://www.alzscot.org/fairdementiacare (Last accessed 12th March 2019)

Abreu W, Tolson D, Jackson A, \& Costa N (2018) A cross-sectional study of family caregiver burden and psychological distress linked to frailty and functional dependency of a relative with advanced dementia. Dementia. 1471301218773842.

Amador S, Goodman C, Robinson L, et al (2016) UK end-of-life care services in dementia, initiatives and sustainability: results of a national online survey. BMJ Support Palliative Care. Epub ahead of print 14. October 2016. DOI: 10.1136/ bmjspcare-2016-001138.

Aminoff B (2014) Prognosis of short survival in patients with advanced dementia as diagnosed by Aminoff suffering syndrome. American Journal of Alzheimers Disease and Other Dementias. 29, 8, 673-677. doi: 10.1177/1533317514539543

Bartlett R, Windemuth-Wolfson L., Oliver K. and Dening T (2017) Suffering with dementia: the other side of "living well". International Psychogeriatrics, 29, 1, 177-179.

Brown, M., Waugh, A., Sharp, B., Duffy, R. and Macrae, R (2018) What are dementia champions and why do we need them. Dementia, 17, 4, 397-400.

Care Council for Wales (2016) Good Work: A Dementia Learning and Development Framework for Wales. Available at: https://socialcare.wales/cms_assets/file-uploads/Good-Work-DementiaLearning-And-Development-Framework.pdf (Last accessed $12^{\text {th }}$ March 2019)

Department of Health (2016) Making a Difference in Dementia Nursing: Vision and Strategy refreshed edition. London, Department of Health. Available at:

https://assets.publishing.service.gov.uk/government/uploads/system/uploads/attachment_data/file /554296/Dementia_nursing_strategy.pdf (Last accessed $12^{\text {th }}$ January 2019) 
Dixon J, King D, Matosevic T, Clark M and Knapp M (2015) Equity in Palliative Care in the UK, PSSRU, London: London School of Economics/Marie Curie

Gov. UK. (2016) Challenge on Dementia 2020: Implementation Plan. Available at:

https://www.gov.uk/government/publications/challenge-on-dementia-2020-implementation-plan (Last accessed 1st July 2019)

Hanson E, Hellstrom A, Sandvid, A, Jackson G, Macrae R, Waugh A, Abreu W \& Tolson D (2016) The extended palliative phase of dementia - an integrative literature review. Dementia DOI: 10:1177/1471301216659797.

Holmerova I, Waugh A, Macrae R, Sandvide A, Hansen E, Jackson G, Watchman K, Tolson D (2016) Dementia Palliare Best Practice Statement, University of the West of Scotland. DOI:

10.13140/RG.2.1.3382.7446.

Hvalič-Touzery S, BrigitaSkela-Savič B,' Macrae R, Jack-Waugh A, Tolson D, Hellström A, Abreu W, Pesjak K (2018)The provision of accredited higher education on dementia in six European countries: An exploratory study. Nurse Education Today. 60, 161-169. doi: 10.1016/j.nedt.2017.10.010.

Knifton C, MacRae R, Jack-Waugh A, Brown M, Surr C, Thompson R \& Baillie L (2019) Dementia education in Higher Education Institutions, now and in the future: the role of the professional regulatory bodies in the UK. Journal of Research in Nursing. 24, 3-4, p. 271-278

Lillo-Crespo M, Riquelme Galindo J, Macrae R, Abreu W, Hanson E, Holmerova I, Cabanero M, Ferrer $R$ and Tolson D (2018) Experiences of Advanced Dementia Care in seven European countries: Implications for Educating the Workforce. Global Health Action. 11, 1, 1-12

Lithgow S, Jackson A, \& Browne D (2012) Estimating the prevalence of dementia: cognitive screening in Glasgow nursing homes. International Journal of Geriatric Psychiatry. 27, 8), 785-791.

Lucca U, Tettamanti M, Logroscino G, et al (2015) Prevalence of Dementia in the Oldest Old: The Monzino 80-plus Popu-lation Based Study. Alzheimer's \& Dementia, 11, 258-270.

Matthews E, Arthur A, Barnes E et al \& Medical Research Council Cognitive Function and Ageing Collaboration (2013) A two-decade comparison of prevalence of dementia in individuals aged 65 
years and older from three geographical areas of England: results of the Cognitive Function and Ageing Study I and II. The Lancet, 382, 9902, 1405-1412.

Muangpaisan W. (2007) Clinical differences between four common dementia syndromes. Geriatrics and Aging. 10, 7, 425-429.

Murphy E, Froggatt K, Connolly S, O'Shea E, Sampson L, Casey D \& Devane D (2016). Palliative care interventions in advanced dementia. Cochrane database of systematic reviews, (12).

National Institute of Health and Care Excellence (2018) Dementia: assessment, management and support for people living with dementia and their carers. NICE guideline (NG97). Available at https://www.nice.org.uk/guidance/ng97[Lats accessed $16^{\text {th }}$ March 2019)

Northern Ireland Executive (2016) Northern Ireland Dementia Learning and Development Framework. Available at: http://www.hscboard.hscni.net/dementia/learning-developmentframework/ (Last accessed 21 ${ }^{\text {st }}$ March 2019)

Nourhashemi F, Gillette S, Cantet C, et al (2012) End-of-life care for persons with advanced Alzheimer disease: design and baseline data from the ALFINE study. The Journal of Nutrition Health \& Aging, 16, 5, 457-461.

Nursing and Midwifery Council (2018) Part 3: Standards for pre-registration nursing programmes. Available at: https://www.nmc.org.uk/globalassets/sitedocuments/educationstandards/programme-standards-nursing.pdf (Last accessed 21st March 2019).

Prince M, Knapp M, Guerchet M, et al (2014). Dementia UK: Update. Alzheimer's Society. Available at: https://www.alzheimers.org.uk/sites/default/files/migrate/downloads/dementia_uk_update.pdf [Accessed 5th March 2019]

Reisberg B, Wegiel J, Franssen E, Kadiyala S, Auer S, Souren L, Sabbagh M and Golomb J (2006) Clinical features of severe dementia: staging. Severe dementia, Chichester: Wiley Sampson E (2010) Palliative care for people with dementia. British Medical Bulletin. 96, 159-174. doi: $10.1093 / \mathrm{bmb} / \mathrm{ldq024}$ 
Sampson E, Candy B, Davis S, Gola A, Harrington J, King M, Kupeli N, Leavey G, Moore K Nazareth I, Omar RZ, VickerstaffV and Jones L (2018) Living and dying with advanced dementia: A prospective cohort study of symptoms, service use and care at the end of life. Palliative Medicine 32, 3, 668-681. Schafirovits-Morillo L and Suemoto K. (2010) Severe Dementia: A review on diagnosis, therapeutic management and ethical issues. Dementia \& Neuropsychologia. 4, 3, 158-164.

Scottish Social services Council and NHS Education for Scotland (2011) Promoting excellence: A framework for all health and social services staff working with people with dementia, their families and carers. Available at:

http://www.scotland.gov.uk/Resource/Doc/350174/0117211.pdfhttps://www2.gov.scot/resource/d oc/350174/0117211.pdf (Last accessed 4th March 2019)

Scottish Government (2017) Scotland's Third Dementia Strategy 2017-2020. The Scottish Government. ISBN: 978652-840-7 https://www.gov.scot/publications/scotlands-national-dementiastrategy-2017-2020/

Semrau M, Burns A, Djukic-Dejanovic S, et al on behalf of the International Dementia Alliance (IDEAL) Study Group (2015) Development of an international scale for the assessment and staging of care for dementia. Journal of Alzheimer's Disease. 44, 139-151.

Semrau M, Burns A, Lobo A, Olde Rikert M, Robert P, Schepens M, Stoppe G, Satorius N (2019) Assessment and Staging of Care for People with Dementia: The IDEAL Schedule and its User Manual. Oxford University Press, Oxford.

Tolson D, Fleming A, Hanson, E et al (2016) Achieving Prudent Dementia Care (Palliare): An International Policy and Practice Imperative. International Journal of Integrated Care, 16, 4, 1-11, DOI: http://dx.doi.org/10.5334/ijic.2497

Tolson D, Holmerova I, Macrae R, Waugh A, Hvalic-Touzery S, de Abreu W, Lillo Crespo M, Merta A, and Hanson E (2017) Improving Advanced Dementia Care, an Interprofessional Learning Framework Journal of the American Medical Directors Association http://dx.doi.org/10.1016/j.jamda.2017.03.014

Tolson, D and Jackson, G (2019) Advances in Knowledge in Tolson, D and Jackson, G (eds) Textbook of Dementia Care: An Integrated Approach UK: Routledge. 
World Health Organization (2017) Global action plan on the public health response to dementia 2017-2025. World Health Organization ISBN: 978-92-4-151348-7

Van der Steen T, Dekker L, Gijsberts M, Vermeulen H, Mahler M, Anne-Mei B (2017) Palliative care for people with dementia in the terminal phase: a mixed-methods qualitative study to inform service development. BMC Palliative Care. 16:28 DOI 10.1186/s12904-017-0201-4.

Van der Steen T, Radbruch L, Hertogh M et al. (2014) European Association for Palliative Care (EAPC). White paper defining optimal palliative care in older people with dementia: a Delphi study and recommendations from the European Association for Palliative Care. Palliative Medicine. 28, 3, 197-209.

Voisin, T. and Vellas, B. (2009) Diagnosis and treatment of patients with severe Alzheimer's disease. Drugs \& Aging. 26, 2, 135-144.

Wortmann M. (2012). Dementia: global health priority-highlights from an ADI and World Health Organization report. Alzheimer's Research \& Therapy. 4, 5, 40-43 